\title{
OSSIFICAÇÃO EM PULMÃO DE BOVINO
}

\author{
POR \\ Rubens Escobar Pires \\ Assistente \\ Com estampas. VI-VII
}

Deu entrada em nosso Departamento, em abril de 1937, um pulmão de bovino, mandado de um dos matadouros desta Capital e que apresentava, como anomalia, um estranho endurecimento de certas zonas que rangiam ao corte pela faca. A peça, naturalmente, não veio acompanhada de história clínica, nem tão pouco de uma descrição dos outros órgãos e partes do animal. E, mesmo do pulmão, foram enviados os dois terços inferiores que apresentavam tal anomalia, não sendo possivel um estudo do órgão total, dos gânglios hilares, nem do outro pulmão.

À inspeção, notava-se a pleura que recobria o órgão, em geral lisa, brilhante e transparente, apresentando, no entanto, zonas esbranquiçadas e espessadas de tamanhos variados, de conformação irregular, medindo em média 2 a $3 \mathrm{cms}$. de diâmetro. À palpação, verificou-se que o lobo pulmonar em questão, em sua parte súpero-externa e na parte mais inferior, apresentava-se de consistência normal, havendo aquí e alí ligeira condensação. Na porção média da peça, apanhando-a desde o hilo e caminhando para baixo e para fora, verificou-se a presença de uma larga faixa de tecido grandemente endurecido, continuando-se insensivelmente com o tecido aparentemente normal vizinho e medindo mais ou menos $10 \mathrm{cms}$. de largura.

$\mathrm{O}$ corte, efetuado no plano longitudinal do órgão, revelou uma superfície complexa em sua estrutura, devido, principalmente, à estranha formação que tomava grande parte da peça e já notada à palpação, pela sua dureza. Na superfície de corte, verificou-se a mesma faixa endurecida, atravessando diagonalmente a peça desde o hilo até desaparecer aos poucos no bordo externo e inferior do pulmão, já assinalada no exame externo do órgão. Os limites desta faixa com o tecido pulmonar aparentemente normal não eram nítidos. Nela, a estrutura fazia lembrar um pulmão altamente enfisematoso, mas, que, conservando ainda dilatadas as paredes alveolares, assumia o aspecto de uma esponja. Já ao corte, se nota uma dureza acentuada, parecendo estar o tecido sustentado por uma armadura de lâminas que, à palpação, se assemelhavam a espinhas de peixe. Não se verificou a existência, nessa zona, de exsudatos ou hemorragias grandes e, no tecido 
restante, a expressão fez escorrer um líquido róseo claro, ligeiramente espumoso.

Em algumas zonas, situadas logo abaixo da pleura, verificouse a presença de porções pulmonares circunscritas francamente enfisematosas, e, em outros pontos, condensação e aparência de zonas atelectásicas.

Da peça fixada em formol-salgado a $10 \%$, foram retirados para exame histológico, fragmentos tanto de tecido endurecido como de zonas aparentemente normais e de zonas consideradas intermediárias entre uma e outra. Foram feitas colorações pelo método da hematoxilina-eosina, Van Gieson, Weigert, Hornowsky e Kossa. Fragmentos de tecido endurecido foram submetidos à ação dos ácidos clorídrico, sulfúrico e azótico para verificação da sua natureza, não tendo praticamente desprendido gás.

Em zonas fora do processo em questão, verificou-se que a pleura correspondente às placas esbranquiçadas já descritas macroscopicamente, se apresenta espessada pela formação de um tecido fibroso subepitelial, ao mesmo tempo que apresenta rugosidades que se acolam umas às outras aumentando assim sua espessura. Pelos métodos eletivos de coloração, verificou-se que, em toda a pleura, o tecido elástico está conservado e acompanha, em toda a extensão, as rugosidades das zonas espessadas. Os espessamentos seguem as sissuras naturais do órgão, penetrando profundamente no parênquima. O parênquima pulmonar, nessas zonas, apresenta-se com as paredes alveolares em geral espessadas a custas de um aumento numérico das células epiteliais, que estão tambem hipertrofiadas. A luz dos alvéolos está diminuida, e, em outros lugares, as paredes definitivamente colabadas, mostram franca atelectasia.

O tecido conjuntivo alveolar não se apresenta hipertrofiado, como se verifica pela coloração dos cortes pelo Van Gieson. Não se nota qualquer alteração por parte do sistema vascular a não ser uma discreta hipertrofia das paredes arteriais.

Os pequenos brônquios, salvo discreto exsudato mucoso, nada apresentam digno de nota. Os brônquios médios mantêm o epitélio cilíndrico normal bem como a sua musculatura, porém, no tecido conjuntivo peribronquial da maior parte deles, nota-se um infiltrado parvicelular mais ou menos intenso, predominando os linfocitos. Não havendo, no entanto, qualquer reação maior para o lado do tecido conjuntivo e do sistema vascular do lugar, diagnosticou-se apenas discreta peribronquite crônica. Não só aí como no resto do parênquima, isto é, nas paredes alveolares, espaços interlobulares, etc., o tecido con- 
juntivo não se mostra aumentado. As placas cartilaginosas dos brônquios maiores apresentam, na sua intimidade, formações ósseas compactas em maior ou menor quantidade, havendo em algumas delas, formação de luz no seu interior sem presença de quaisquer elementos figurados. Em um ponto do tecido, na pleura, que penetrava mais ou menos profundamente no parênquima, havia forte impregnação de cálcio, evidenciada pelo método eletivo de coloração de Kossa.

Nas zonas do parênquima endurecido, o aspecto se mostra completamente diverso. Os alvéolos extremamente dilatados, de paredes finas, apresentam roturas frequentes, havendo comunicações entre eles, levando assim a distensões extremas que conferem ao todo o aspecto de tecido enfisematoso em alto grau. Os vasos sanguíneos estão cheios de sangue, havendo, em alguns lugares, extravasamento discreto de sangue para a luz dos alvéolos. Não são encontrados aquí, senão muito discretamente, os sinais de peribronquite crônica verificados em outras zonas. Merecem especial atenção, as formações ósseas presentes na zona em questão. Estão elas espalhadas pelo parênquima pulmonar em conexão íntima com a parede dos alvéolos, de tamanhos e forma variaveis, medindo no máximo de 1 a $2 \mathrm{mms}$. de comprimento e tendo predominantemente a forma de lâminas convexas. Essas formações ósseas, com afinidade acentuada pela hematoxilina, estão dispostas nas paredes dos alvéolos, formando corpo com elas. Essas paredes não se encontram espessadas e o epitélio alveolar recobre diretamente as formações ósseas. O tecido conjuntivo não se encontra hipertrofiado ao redor das lâminas ósseas e o tecido elástico, embora presente e normal, não guarda com as mesmas senão relações de mera vizinhança, não se descobrindo maior intimidade entre elas. Os vasos sanguíneos e os brônquios estão livres do processo, notando-se, porém, uma eventual tendência para transformação óssea das cartilagens bronquiais. As formações ósseas são do tipo lamelar, verificando-se a presença de osteoblastos no seu interior, parecendo que o crescimento se processa pela juxtaposição de novas lamelas formadas por novos osteoblastos, tal como acontece na formação óssea dos canais de Havers.

Os alvéolos sofreram naturalmente devido à presença dessas ossificações, especialmente nas zonas onde elas estão em maior quantidade, alterações profundas tais como atelectasia ou enfisema em grau já muito alto. Em alguns pontos, o epitélio sofreu metaplasia, transformando-se em epitélio cúbico.

A verificação da presença de tecido ósseo em lugares onde normalmente não existe tem sido motivo para pesquisas e publicações, 
pois, no capítulo das metaplasias, é isto um campo fertil não só pela frequência com que tal anomalia aparece, atingindo grande número de tecidos e de órgãos, como tambem pelos vários processos de sua transformação. Numerosos têm sido os trabalhos publicados a respeito, no homem, pois, sua presença foi notada nos musculos, tendões e ligamentos, em vários lugares do sistema circulatório (coração com seus folhetos e vasos), no sistema nervoso, principalmente nas meninges, nas várias partes componentes do olho, nas diferentes partes do aparelho respiratório, nos tumores malignos, nas necroses, etc..

Já não se dá o mesmo na literatura veterinária onde são escassos os trabalhos a respeito, embora o processo de ossificação metaplásica ou heterotópica nos vários órgãos não seja fato raro. Contudo, compulsando a literatura veterinária, pudemos verificar a existência de publicações, referindo-se à presença da metaplasia óssea em vários animais e em diversos órgãos, como coração, pulmões, mesentério, peritoneo, testículo e tireóide de cavalos, bois, cachorros, carneiros, etc..

O aparecimento de tecido ósseo no parênquima pulmonar se intrinca, em última análise, nos problemas gerais das metaplasias e, como tal, obedece aos principios já estabelecidos sobre o assunto.

No pulmão, há vários tecidos capazes de determinar o aparecimento de osso: o tecido cartilaginoso da traquéia e dos brônquios, o tecido conjuntivo, abundantemente difundido, o tecido epitelial dos alvéolos, considerado de natureza mesenquimal, não se levando em conta as necroses frequentes onde a ossificação é fato possivel, como se verifica nos nódulos tuberculosos primários, parasitários, etc..

$\mathrm{Na}$ parede alveolar, encontramos, como elementos constitutivos, os capilares sanguíneos, tecido conjuntivo, tecido elástico e epitélio de revestimento, considerado de natureza mesenquimal e cujas células possuem natureza nitidamente histiocitária.

Alguns autores como KiTT, BRUCKMÜLLER, BURGHARDT, observaram casos, em cães velhos, em que se notava a presença de pequenos nódulos ósseos rodeados de tecido conjuntivo espessado do qual era evidente a sua proveniência, como bem o demonstrou OLT.

Em outros casos, como no de Trolldenier e Bugge, verificouse a presença de depósito de fosfato de cálcio em fibras elásticas do pulmão de uma vaca de 3 anos, que sofria de enterite hipertrófica pseudo-tuberculosa.

JoEsT, em 1910, apresenta um caso em bovino, onde o tecido pulmonar interalveolar mostrou, em região restrita de $5 \mathrm{~cm}$. de largura, formações ósseas lamelares típicas, que atribuiu a uma inflama- 
ção crônica do tecido interalveolar, por ele denominado de pneumonia intersticial ossificante.

ZscHoKKE, em 1920 fazendo revisão das peças existentes no Departamento de Anatomia Patológica da F. M. Veterinária de Zürich, encontrou casos de ossificação pulmonar em animais, de que, um em cavalo portador de formação tumoral do tamanho da cabeça de criança, de consistência pétrea e cuja constituição, embora complexa, foi encarada como adenoma ossificante. Outro caso de pulmão de cabra revelou, alem de processos enfisematosos e edema, formações ósseas lamelares nas paredes alveolares, como tambem a presença de pequenos nódulos de 0,01 a $0,1 \mathrm{~mm}$. formados por carbonato de cálcio. Nesse caso, ZschokкE pensa ter havido primitivamente, uma deposição de carbonato de cálcio no protopiasma das células epiteliais do alvéolo, havendo, secundariamente, formação do processo ossificante em forma lamelar. Os estudos exhaustivos feitos pelo mesmo autor em pulmöes de vaca com tal processo pela sua semelhança com o nosso caso, nos interessaram mais de perto, pois, neles vemos uma explicação verossimil para o processo patológico em questão. ZschокKE descreveu-os histologicamente e os interpretou como um processo exclusivo da parede alveolar, pois, nem a pleura, brônquios, tecido conjuntivo inter-lobular ou vasos sanguíneos eram atingidos. Restava portanto a parede alveolar com seus elementos em causa. Nas pesquisas feitas pelo autor, verificou-se que os capilares sanguíneos, tecido conjuntivo e elástico da parede não estavam comprometidos, o mesmo não acontecendo com o epitélio alveolar que apresentava nítidas modificações resumidas no seguinte: em certas células epiteliais foram verificadas deposições calcáreas, evidenciaveis como linhas ou pequenas massas azuladas. As células assim atingidas aumentam, chegando a medir 50 a $60 \mu$ de tamanho e projetando-se para dentro da luz dos alvéolos. Neste estadio, as células ossificadas formam em conjunto, lamínulas curvas, que, em certos pontos, aumentam de espessura, havendo mesmo penetração em outros alvéolos. Em fase mais avançada, verifica-se a presença, no interior da substância fundamental, de núcleos estrelados ou em forma de bastões de 2 a $3 \mu$ de tamanho e rodeados de uma zona clara, sendo identificados como núcleos de osteoblastos. O crescimento daí por diante se dá pela juxtaposição, em camadas concêntricas, de substância fundamental, formada por novos osteoblastos, derivados do epitélio alveolar que recobre o núcleo ósseo primitivo. Secundariamente, a ossificação produz as lesões enfisematosas bem como os extravasamentos sanguíneos verificados em alguns alvéolos. O autor considera por fim, que, um estímulo especial, no 
caso podendo provir de uma peribronquite existente, as células epiteliais ganhariam afinidade pelo cálcio, seguindo-se então o processo ossificante e daí o nome de ossificação metaplásica.

Pelo exame dos diversos trabalhos sobre ossificação pulmonar, verificamos que, se de um lado se realça o papel desempenhado pelo tecido ainda com capacidade formadora mesenquimal, por outro, vários são os meios utilizados para o aparecimento metaplásico.

Aschoff considerou, na traquéia, os nódulos ósseos como derivados da mucosa de revestimento (tecido conjuntivo submucoso). AMORIM, nos casos em que verificou a presença de tecido ósseo nos brônquios, fê-los derivar dos elementos conjuntivos peribronquiais, dando como provavel a sua semelhança com a traqueopatia osteoplástica de Aschoff, atribuindo a ambas origem mesenquimal. Nos casos descritos por KitT, BRuckmüller, Bughardt, em cães velhos e, em bovino, por KITT, o tecido conjuntivo interalveolar, interlobular e peribronquial era o responsavel pelo processo patológico. Já o caso de JoEsT, descrito em 1910, apresenta semelhança com os de ZsCHOKKE, sendo portanto processo apenas do epitélio alveolar.

Não pode ser levado em conta o fato de, em determinados processos patológicos, como, por exemplo, reabsorção óssea intensa, haver deposição de sais de cálcio sobre as fibras elásticas, sem aparecimento de verdadeira substância óssea. E' assim o caso verificado em vaca, por Trolldenier e Bugge, já referido acima. Não devem ser enquadrados nos casos acima, as formações ósseas de aspecto blastomatoso, como o da observação de ZSCHOKKE em cavalo e os osteomas reticulares observados por AMORIM e outros.

Verifica-se portanto que todos os casos de ossificação heterotópica no pulmão têm, como ponto de partida, um elemento de tecido mesenquimal, ainda com capacidade formadora de tecido diferenciado como é o ósseo. Só assim se pode explicar o aparecimento do tecido ósseo no pulmão, obedecendo aos principios ainda aceitos que regem formação das metaplasias, como por exemplo somente ser possivel de formar tecido diferenciado, aqueles que conservam capacidade formadora embrionária.

Para o tecido epitelial dos alvéolos esse problema se mostra mais complexo, pois, mesmo sua origem embrionária vem dando motivo a controvérsias ainda não terminadas. A opinião de LANG (1925) de serem as células nucleadas que representam o epitélio dos alvéolos de origem puramente mesenquimal vem explicar os achados histológicos em ossificação atingindo somente paredes alveolares tal como em nosso caso. 
Pelas pesquisas efetuadas em nosso caso (método de KoSSA), não verificamos deposição alguma de cálcio nas células ou em qualquer outra parte do parênquima pulmonar, a não ser em uma zona muito restrita da pleura. O osso neoformado, como vimos, pela descrição histológica, se originava diretamente do epitélio, confirmando desta maneira, os achados de ZschoKKe em seus casos e a opinião de LANG a respeito da potencialidade histiocitária das células nucleadas do epitélio alveolar.

Cremos que o processo se inicia por modificação da orientação de tais células, que assumem carater francamente osteoblástico, formando então a substância óssea fundamental. $O$ porque dessa transformação ainda permanece como incógnita, parecendo, no entanto, que estímulos tais como reações inflamatórias crônicas, possam determiná-las.

\section{RESUMO}

0 artigo trata de um caso de ossificação em pulmão de bovino, atingindo exclusivamente a parede alveolar, tendo como origem seu epitélio. Sendo um exemplo típico de metaplasia, naturalmente obedece aos principios em que esta se assenta e porisso somente admitindo a natureza mesenquimal do epitélio alveolar é que se pode encontrar uma explicação verossimil para o processo em questão.

Os casos relatados na literatura veterinária são em pequeno número ressaltando-se os de ZschoKKe, de Zürich, cujas pesquisas histológicas representam base segura para um melhor estudo da metaplasia óssea no pulmão.

\section{SUMMARY}

The paper shows a case of ossification in a bovine lung, localized in the alveolar wall exclusively, originating from its epithelial loyer. It is a typical metaplasia, and so, it obeys the principles on which it is based and only admiting the mesenchimal nature of the alveolar epithelium, it can find a possible explanation about the process.

There are few cases related in the Veterinary literature, but the ZsCHOKKE's ones, with its histologic researchs, represent a firm base for a better study of the metaplastic ossification of the lung

\section{BIBLIOGRAFIA}

AмоRiм, M. - 1936 - Uber seltenen Formen von Knochenbildungen in der Lunge und den kleinen Bronchien. Beitr. pathol. Anat., 97 (1):184-191.

Aschoff, L. - 1910 - Über tracheopathia osteoplastica. Verhandl. d. Deutschen Path. Ges. 14. Cit. por M. Amorim.

BRUCKMÜLLER - 1869 - Lehrb. d. path. Zootomie. cit. por E. Joest.

BUGGE - $1910-$ Zschr. f. Fleisch-Hyg. cit. por W. Zschokke. 
Burghardt $-1907-$ Chron. Veränderungen der Hundelungen. Diss. Leipzig. cit. por E. Joest.

JoEst, E. - 1924 - Handbuch der Speziellen pathologischen Anatomie der Haustiere 3:624-626; Berlin, Richard Schoetz.

KrTT, T. - 1923 - Lehrbuch der pathologischen Anatomie der Haustiere 3:715-717. 5 Aufl. Stuttgart, Ferdinand Enke.

LANG, F. - 1925 - The reaction of lung tissue to tuberculous infection in vitro. J. Infect. Dis., 37, 430 cit. por A. Maximow.

LANG, F. - 1926 - Ueber Gewebskulturen der Lunge. Arch. f. exper. Zellforsch., bes. Gewebezüchtung (Explanation), 2, 93, cit. por A. Maximow.

Our - Arch. f. wiss. Tierhlk. 36, suppl, cit. por E. Joest.

ZscноккE, W. - 1920 - Über Ossifikationen der Lunge bei Tieren. Schw. Arch. Tierhlk., 62 (1) :1-24.

\section{EXPLICAÇÃO DAS FIGURAS}

\section{Estampa VI}

Fig. 1 - Superfície de córte de pulmão de bovino em que se nota a estrutura esponjosa assumida pelo órgão, no processo ossificante.

Fig. 2 - Microfotografia, em pequeno aumento, para visão em conjunto de uma preparação histológica em que se nota o enfisema acentuado e as formações osseas descritas no texto. (obj. Mikrotar $3 \mathrm{~cm}$ ).

\section{Estampa VII}

Fig. 3 - Microfotografia, com maior aumento, de um córte histológico apresentando em detalhe, as formações ósseas das paredes alveolares. (Obj. 20 ocular 4).

Fig. 4 - Microfotografia de um córte histológico onde se nota o osso em forma convexa e recoberto diretamente por epitélio alveolar. (Obj. 20 ocular 4). 

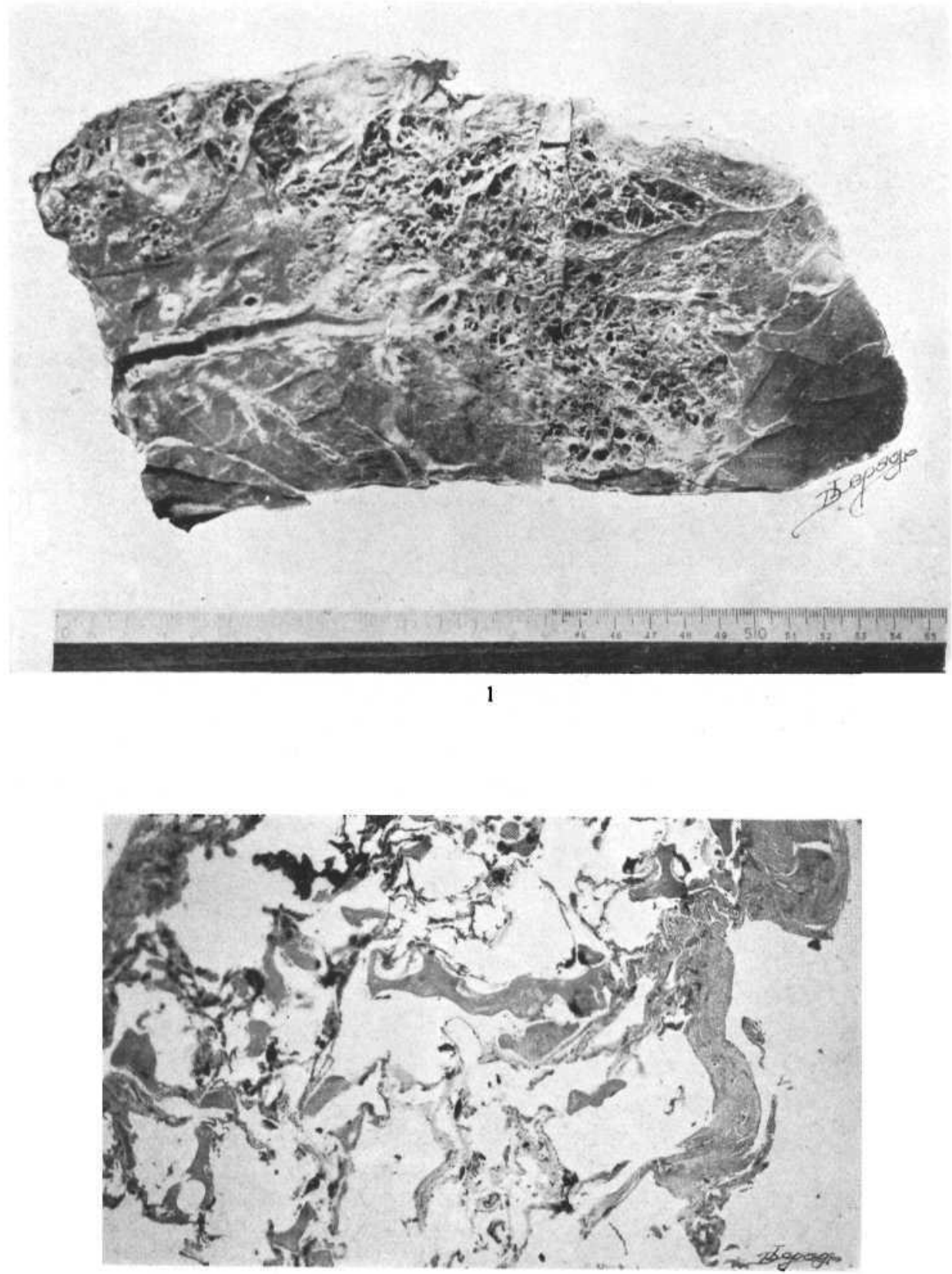


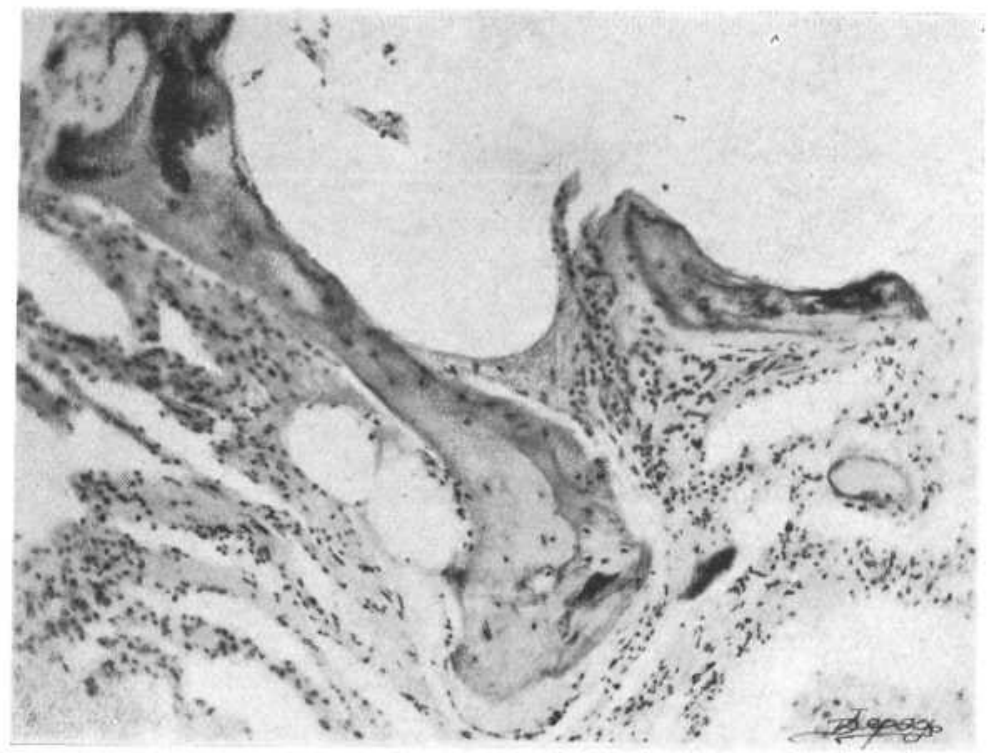

3

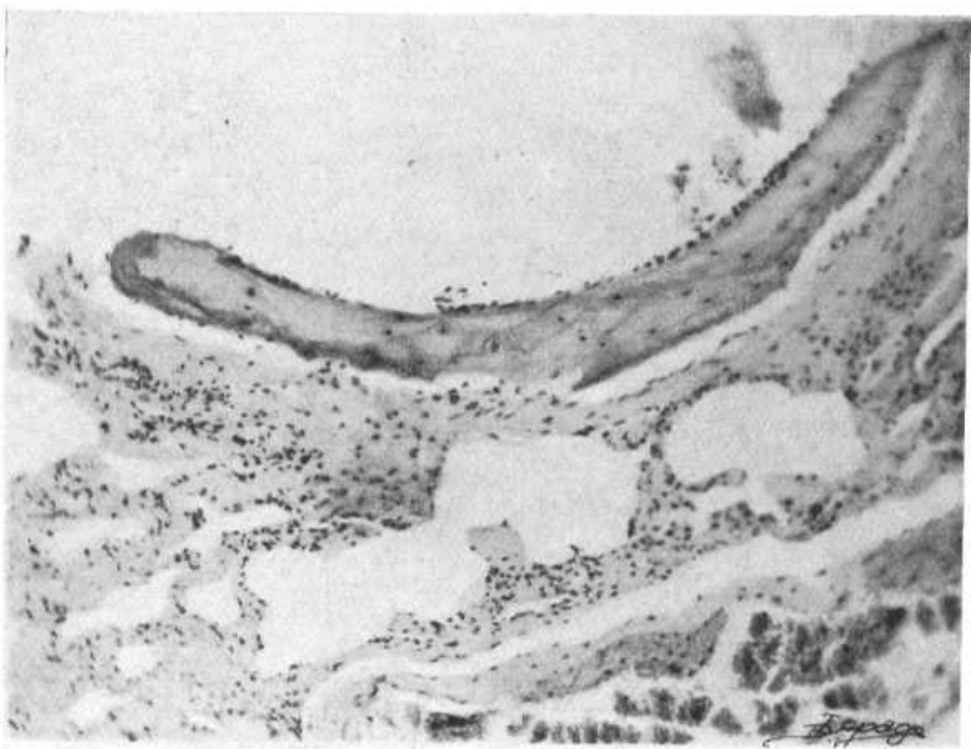

